\title{
Self as other: distanciation and reflexivity in ancient Greek divination
}

\section{Introduction}

This essay examines some of the ways in which the practice of oracular consultation in ancient Greece - as both an individual experience and a cultural institution expressed and, in turn, reinforced the sense of the mortal self as dividual and subject to uncertainty. It argues that both those who were possessed and gave oracles, and those who received oracles would have experienced a sense of 'distanciation', that is, a reflexive sense of distance from self. In the space created by that sense of distance was located the potential to perceive oneself as intersubjective, prompted by an understanding of the role of the divine in mortal life, and a strong sense of irony, generated by comprehension of the contrast between divine and mortal knowledge. This was linked, in turn, to a profound acknowledgement of the persistent presence of uncertainty in mortal experience. The sense of distanciation was, in the case of both oracle giver and oracle receiver, generated not only by the embodied experience of openness to the divine, but also by participation in the shared narratives of such experiences - and by the relationship between the two.

In making this argument, I am building on two previous articles, details of which I include here at the request of the editors, because it will help to make more apparent the connections between this essay and others in this publication, as well as give a fuller overview of this essay's argument (Eidinow 2013; 2019a respectively). The first article, 'Oracular Consultation, Fate, and the Concept of the Individual,' sets out to explore how those who consulted oracles perceived themselves as 'individuals', examining the conception of the self that they held, and how this influenced their expectations of the oracular process and its outcome. As a first step, the article seeks to make explicit common models of the self in current Western culture, which tend to picture the self as 'more autonomous from other people and outside influences [...] than in other times and places' (Strauss, Quinn 1997, 28). Indeed, Clifford Geertz has suggested that this idea of the self, as 'a bounded, unique, more or less integrated motivational and cognitive universe, a dynamic centre of awareness, emotion, judgment, and action organized into a distinctive whole and set contrastively both against other such wholes and against its social and natural background' is 'a rather peculiar idea within the context of the world's cultures' (Geertz 1983, 59). The article raises some alternative models of the self, which will also be relevant to the essay in this 
publication: specifically, it focuses on the idea of the 'dividual', which conceives of the body and self as comprising a 'microcosm of relations' (Strathern 1988, 131). While this is most starkly seen in analyses of conceptions of self in nonWestern cultures (for example, and in particular, in Marilyn Strathern's research in the Highlands of Papua, New Guinea), as others have argued, this kind of relationality with others can also be observed as an element of self-conceptions in Western cultures: the self emerges in different cultures, 'precisely from that tension between dividual and individual aspects/relations', as Edward LiPuma has suggested (LiPuma 1998, 56-61, and quotation 57; his italics). The article goes on to explore how a relational model of the self could be useful in understanding the process of oracular consultation: it argues that there is evidence that 'ancient Greek men and women conceived of the self in relational terms, and that this relationality included interdependence with supernatural forces (and, in turn, their inter-relations) with regard to both individual character and life-course' (Eidinow 2013, 37). Looking more specifically at the evidence for oracular consultations, it posits that 'those who consulted Oracles perceived themselves to be engaged in working out their circumstances in communion with supernatural forces' (ibid., 32).

The second article, 'Tú $\chi \alpha$ at the Oracle of Zeus, Dodona,' develops these ideas: from an analysis of the Dodona oracle question tablets, it argues that among those supernatural forces, T/tyche appears to have played a particularly significant role in the framing of possibilities by consultants of that oracle. Rather than providing evidence of the attempt to master $T / t y c h e$, the explicit references to it can be argued to indicate acknowledgment of the continuing presence of uncertainty in daily life - even in a context of oracular consultation and the attempt to seek answers from Zeus (Eidinow 2019a). As that article argues, while, at one level, being simply an expression (and reinforcement) of uncertainty about the future, the appearance of $T /$ tyche across the corpus of texts also evokes a key epistemological contrast inherent in oracular consultation, insofar as it juxtaposes divine foreknowledge with mortal lack of knowledge about future events.

The present essay sets out a further strand of this overall view of the ontological (and experiential) framing of oracular consultation in ancient Greek culture. Looking at oracular consultation from the points of view of both those who gave and those who received oracles, this essay will explore the interactions between narrative and action, the ways in which these prompted processes of distanciation and reflexivity, and how these shaped, and were shaped by, the perception of self. 


\section{Distanciation}

The concept of 'distanciation' can best be illustrated through a case study of spirit possession made by the anthropologist Michael Lambek (2003). The individual in question, a young man called Ali, was from the Western Indian Ocean island of Mayotte. During an initial period of training in the French army at Nantes, he became very ill 'every time he put on his uniform or set foot on the military base' (ibid., 45); he identified the illness as rheumatism, and described how he became almost unable to walk. His mother, who was upset and frightened by Ali's decision to join the army (the Gulf War had just begun at this time) explained to Ali that the symptoms were sent by the family spirit, the trumba ny razaña. Trumbas are Malagasy spirits, who usually belong to the royal Sakalava descent group (dating back to before 1700); they 'occupy' specific mediums (ibid., 57 n. 7; see Lambek 1981; 1993; 2002). Ali's mother's trumba was a male spirit and had inhabited a number of members of the family (Ali's mother, his wife's father's older brother, several of Ali's older sisters).

Lambek has noted how the trumba 'serves, in part, as a sign of the unity, distinctiveness, and continuity of the family' (Lambek 2003, 47 and citing Lambek 1988). But there are other implications of possession that are important here. Observing the effects of his experience on Ali, Lambek argues that lives that are lived in the presence of, or with the experience of, possession are lives that 'become objects of contemplation, interrogation, identification, and edification for those around them'; the process of possession is both an immediate - and painful - experience and one that is 'distanced and objectified sufficiently to be available to others in the form of a narrative' (Lambek 2003, 54 and 55, respectively). He goes on to observe that this is an 'intrinsically ironic' experience, in which irony is understood as 'a disconnection between a speaker and his interlocutor, or between the speaker and that which is spoken about, or even between the speaker and himself' (ibid., 51 quoting from Trilling 1971, 12 for the definition of irony).

Although Lambek does not use the term 'distanciation' in this chapter, Janice Boddy's afterword to another collection on this topic (in which Lambek's contribution discusses the possession of a young man by a sailor spirit) offers a helpful and apposite reflection on this theme (Boddy 1998 [she discusses Lambek 1998]). Boddy notes how the process of relating to spirit(s) and the experience of possession mean that both spirits and host are increasingly objectified: she observes how the "complex interplay between distinctive persons housed in a single material body creates a potential for "absence" or detachment of body from person that is productive of reflexivity' (ibid., 258). Moreover, those who witness or participate in the episode of possession may also experience distanciation, presumably because 
of the way it prompts both reflection among those observing on the potential for them to experience something similar themselves, and, therefore, reflexivity, that is, consideration of the nature of their own personhood. ${ }^{1}$

Drawing on these ideas, this essay suggests that ancient processes of divination may have prompted a similar experience of 'distanciation'. The parallel works most obviously for those who were described as being possessed and delivering oracular pronouncements, such as the Pythia. However, while I will discuss this aspect first, I will suggest that recipients of oracles also experienced distanciation, engaging in a resulting process of reflexivity, specifically because of their participation in the entextualization of their own and others' experiences. ${ }^{2}$ This shaped their engagement with and understanding of the oracular process as ironic; and, as such, it also played a key role in establishing the self as crucially, even dangerously, relational in its composition, and indeterminate in its future.

\section{The possessed}

The idea that the Pythia was considered to have been possessed is not generally cast into doubt. The answer to the question of how this occurred, however, has been theorized in a variety of ways. Indeed, scholarship on the role and behaviours of the Pythia can be described as reflecting the cultural frames of those providing the analysis, with a particular emphasis on the factor of her gender in dictating assumptions about her role and activities (as Lisa Maurizio has clearly analysed: see Maurizio 1995, esp. 70-72). In contrast, Maurizio has demonstrated in detail how parallels from anthropological explorations of possession in different cultures may offer a different perspective, which returns agency to the figure

\footnotetext{
1 Lynch (2000, 27-34, cited in Stausberg 2006, 628) has ably demonstrated how widely the term 'reflexivity' has been used across the humanities, and the potentially problematic breadth of its meaning. However, there are some basic meanings that are helpful in exploring the possible interaction between oracular consultation, oracular narratives, and people's sense of self. In this essay, I draw on Babcock's helpful differentiation between reflection and reflexivity, which is, appropriately, first introduced through consideration of the myth of Narcissus. She observes of the mythic figure (Babcock 1980, 2): 'He is reflective, but he is not reflexive - that is, he is conscious of himself as an other, but he is not conscious of being self-conscious of himself as an other, and hence not able to detach himself from, understand, survive, or even laugh at this initial experience of alienation'.

2 In this latter group, I include both the individual or group making the divinatory enquiry, and the individuals or groups who will have heard or read about the enquiry and its result in some other (narrative) context, be that an oral or written account.
} 
of the Pythia 'as the conduit of divine knowledge' (Maurizio 1995, 84). This essay accepts her argument that the Pythia's was a culturally mediated form of possession, not one that was physiologically induced by substances or gases, and was most likely an altered state of consciousness. ${ }^{3}$

This still leaves open, however, what has become one of the key questions to beset scholarship on the oracle at Delphi: the extent to which the Pythia was responsible for her own pronouncements. Again, it is possible to chart the changes in scholarly responses: earlier scholarship asserted that the Pythia's utterances were incomprehensible and incoherent, reflecting her (it was assumed) frenzied state (e.g., Bouché-Leclerque 1880, 96f.; Flacelière 1938, 104f.; 1965, 50-52; Parke, Wormell 1956a, 33; Whittaker 1965, 26; Burkert 1985, 116). More recently, scholars have observed that the ancient sources suggest rather that the Pythia spoke directly, and coherently, to those who came to consult her (e.g., Flower 2008, 217 adduces the accounts that tell of the Pythia being bribed). Important variations to this argument have been made: for example, some propose that the Pythia gave answers directly to consultants, but these were likely to have been brief (e.g., a straightforward yes or no, or a selection of one of two alternatives), and were then developed into elaborate hexametrical poems by poets employed at the sanctuary for these purposes (Fontenrose 1978, 11-57; McLeod 1961, 320; Bowden 2005, 22-5, and 33f.). In contrast, other scholars have observed that there is no reason why a woman, living in a culture in which she was used to hearing and speaking epic poetry and prayers, could not have composed these lines herself (Maurizio 1995, 84-86.; Flower 2008, 221).

It is helpful here to consider why the question is so difficult to answer. In part, obviously, this is because there is no evidence that illuminates for us the Pythia's own experience of her role and possession (as for Lambek's Ali, above); reflections on this aspect must be drawn, as best we can, from observers' descriptions of these consultations. In turn, it is important to note that for the Greeks themselves, it appears not to have been an issue. ${ }^{4}$ Evidence shows that the god himself was understood to have spoken: this includes epigraphic records of oracles delivered at Delphi; while literary references to consultations are phrased in a similar

3 See Lehoux 2007 for discussion of the evidence for and against the idea that the Pythia was drugged. See Chalupa (2014) for an assessment of the Pythia's state during consultations as exhibiting many of the symptoms of (intentionally and routinely) induced patterned dissociative identity disorder and Deeley (2019) on 'a cognitive reconstruction' of the Pythia's possession.

4 At least that is, until Plutarch writes a dialogue on 'The oracles at Delphi no longer given in verse' (Mor. 394D-409D). 
way. ${ }^{5}$ Fuller descriptions of the process of consultation offer further detail. As an example, consider the story of Croesus' so-called 'test' of the oracles, as given by Herodotus. ${ }^{6}$ The Pythia's response to Croesus' initial question is well known:

I know the number of the grains of sand and the extent of the sea, And understand the mute and hear the voiceless. The smell has come to my senses of a strong-shelled tortoise Boiling in a cauldron together with a lamb's flesh, Under which is bronze and over which is bronze.

(Hdt. 1.47.3; trans. Godley)

Exactly who is understood to be speaking - woman or god - is not made clear: the ambiguity surrounding the identity of the giver of the oracle is maintained by Herodotus, who observes that the ambassadors enter the megaron (where the Pythia is seated) and ask their question of the god; the Pythia then replies with these words, which claim a set of more-than-mortal abilities (Hdt. 1.47.2). The response focuses on the speaker's physical senses and emphasises how far they reach: the verses proclaim their owner's capacity to see detail (grains of sand) and distance (the sea's measures). It then boasts of the speaker's capacity to hear the voiceless, and understand what is senseless.

The story is, of course, a traditional tale, and as other sources suggest, the imagery it employs was proverbial (Pind. Ol. 2.95-10; Pind. Ol. 13.43-46; Pind. Pyth. 9.43-49). While it offers little information about the process of oracular delivery, it may, nevertheless, give some insight into how this culture understood some aspects of the experience of possession. The invocation of the senses sight, smell, hearing, and comprehension - indicates that human physical functions continue, but are, as it were, extended to discern what (to all intents and purposes) is not normally perceptible by mortals.

Are we to understand that the Pythia herself undergoes these remarkable sensory experiences? Again, this is part of the puzzling intersubjectivity of the Pythia, as Herodotus evokes it. Something similar is described as happening to the prophetess Cassandra, as she is depicted in Aeschylus' Agamemnon, although in her case, the information she receives, which leads her to prophesy, comes in the form of visions and smells of events that are temporally,

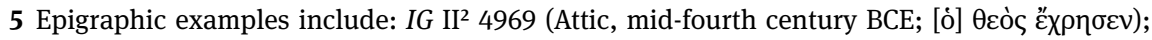
I. Epidamnos T 514 (decree of Epidamnos, erected at Magnesia on the Maeander, third centu-

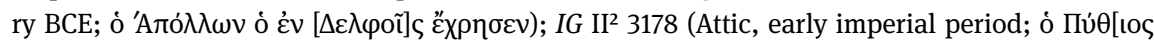

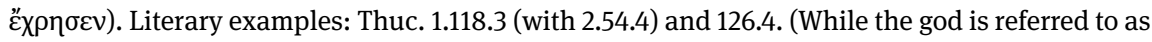

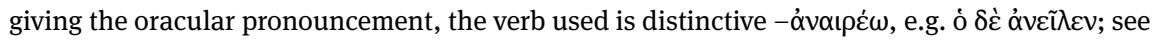
discussion Fontenrose 1978, 219-23).

6 Scholarship has generally condemned Croesus' behaviour, but see Eidinow 2019b. 
rather than physically distant, that is, they have yet to happen (Aesch. Ag. 1214-41, 1256-94 [visions], 1309 [smells]). Cassandra introduces her experience of prophesy in terms that suggest she finds it unpleasant. ${ }^{7}$ Her seeming reluctance to prophesy seems to be accompanied not only by distress at what she is seeing, but also by physical pain: she mentions her 'agony' and the 'fire' that comes upon her. But we must be cautious in drawing any general conclusions. This is, of course, a character for whom the gift of prophecy is difficult (her prophetic powers were a gift; but her punishment, for refusing sex with Apollo, was that her prophecies were not believed): we might expect it to be unpleasant (Aesch. Ag. 1207).

Indeed, the idea of being 'possessed' or entheos (meaning literally, 'the body has a god within it') was also, in some other tragic cases, portrayed as a result of divine punishment, in the form of extreme emotional or physical illness. ${ }^{8}$ For example, in Euripides' Hippolytos, Phaedra is sick with passion and the chorus ask her if she is entheos or 'possessed'; the gods who are named as potentially responsible include Pan, Hekate, the Korybantes or Kybele, or even Dictynna, who may be punishing Phaedra (for an unknown error). ${ }^{9}$ This vision of erotic possession is atypical, or rather, it is characteristic of its (tragic) genre; as suggested by Xenophon's comments in the Symposium, when he describes how those possessed by gods, 'have a tendency to be sterner of countenance, more terrifying of voice, and more vehement', in comparison with those inspired by Love who have 'a more tender look, subdue their voices to more gentle tones, and assume a supremely noble bearing' (Xen. Symp. 1.10; trans. Marchant).

Nevertheless, the potential for prophetic possession to become pathological is suggested by the account by Plutarch of the frenzied response (followed by her death) of a Pythia at Delphi who was forced to prophesy unwillingly. Various physical symptoms are provided in the description: the priestess's harsh voice is a sign that the ritual is not proceeding as it should, along with a comparison

7 Aesch. Ag. 1l. 1214-16 (trans. Smyth): 'Ah, ah! Oh, oh, the agony! Once more the dreadful throes

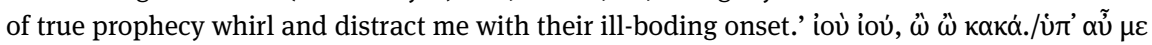

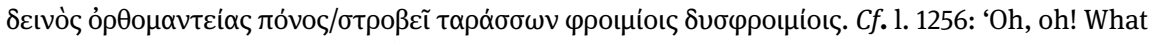

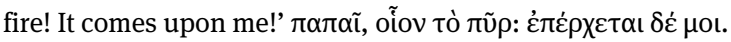

8 The question of the meaning of entheos, and the closely related term enthousiasmos and their many manifestations, is greater than the remit of this essay can support; but see discussion Dodds 1951, 64-101 (87, n. 41 for the phrase 'the body has a god within it'); see also Bremmer 1984, 267-86; Burkert 1985, 109-11; Graf 2009.

9 Eur. Hipp. 141-50; I am not here discussing the possession of the maenads, which uses the same term (e.g., Soph. Ant. 964, also, in a simile for martial frenzy, Aesch. Theb. 497), and see Lyk. Alex. 28 with n. ad loc. in Hornblower 2015. 
of her physical response to 'a laboring ship [...] filled with a mighty and baleful spirit' (Plut. Mor. 438B-C; trans. Cole Babbitt). In the end, Plutarch describes how the woman becomes frenzied and runs towards the exit, before throwing herself down, and dying a few days later. If we are trying to understand better the experience of possession, then this account seems to describe the feeling of an inner force with which the woman was struggling. The focus on the Pythia's voice is also noteworthy, especially since, in a passage close by, the Pythia, when she is in the right mood to surrender to the god, is compared to a musical instrument, prepared and tuneful (Plut. Mor. 437D-E).

As noted, these passages provide an observer's perception of mantic possession, and perhaps are better described or understood as revealing to us something of how ancient Greek society imagined the possible gamut of experiences involved. The insights they offer are further reinforced through descriptions of mantic possession that, while engaging less impressive supernatural entities, offer further detail. The chorus leader in Aristophanes' Wasps introduces one rather surprising example, in which the poet is cast as the possessing spirit. In a description of how the poet has behaved in the past when practising his craft, he compares him to a possessing spirit called Eurycles: 'At first it was not openly but secretly, giving assistance to other poets, slipping into other people's stomachs in imitation of the prophecy and method of the seer Eurycles, that he poured forth many comic words' (Ar. Vesp. 1019f.; trans. Sommerstein 1983). Eurycles was, according to a scholiast, a prophet who manifested himself through others; in this passage, the name may be meant to indicate the mouthpiece of the spirit, or, indeed, the spirit itself. Indeed, that it is impossible to tell which is meant - the spirit, or the body that is possessed by the spirit - may also provide some insight into the cultural perception of the phenomenon of spirit possession.

Either way, Aristophanes' description offers a rather vivid image, albeit, a brief, and above all, a comic image, of one way in which a possessing spirit may have been understood to inhabit a mortal body. But to explore how this picture of the possessing spirit actually being within the body was more than simply a literary image, we can turn to other references to possessed seers. In particular, it appears that the mention of the 'belly' as Eurycles's hiding place is for more than comic effect. It is surely a reference to the engastrimythoi (lit. 'belly talkers', also often translated as 'ventriloquists'), who were seers who gave prophecies from their stomachs and are mentioned, in passing, in a Hippocratic treatise, Epidemics (see Hipp. Epid. 5.63, 7.28; the case studies are the same). The passage gives some idea of what belly-talking looked or rather sounded like: the patient, Polemarchos' wife, is said to have 'breathed like a diver who has surfaced. She made a noise from her chest. It was something like the so-called belly talkers make' (trans. Smith). 
Further information about the behaviour of individuals who claimed to be possessed is given by an admittedly later source: Lamprias in Plutarch's dialogue De defectu oraculorum (Plut. Mor. 414E). He describes the so-called Pythones, who were once called Eurycleis - a change of name that suggests that the cultural framing of 'possession' had by now begun to elide the idea of Delphic possession with other similar phenomena. The Pythones were seers who claimed that the god would enter their bodies and speak through their mouths and voices 'as instruments'; the Greek term (organois) suggests a tool (an inanimate object) but can also be used to indicate an organ 'of sense or apprehension', which indicates a more interactive relationship with the divine in this instance (see LSJ s.v. for references); it also brings back to mind the earlier description of the Pythia herself in terms of a musical instrument - and the harshness of her delivery when the timing of consultation was awry.

This brief overview of descriptions of mantic possession is not intended as an explanation of the physical or mental states of the Pythia and other possessed seers. Rather, it is intended to provide some insight into the larger cultural framing of the divine-mortal interaction understood to take place during such possession. It suggests, through a variety of imagery, a picture of the possessing spirit and the mortal body as separate entities, which somehow must find a shared material space. It may be that another reference to Eurycles, which we find in Plato's Sophist can further our understanding of how that sharing was imagined. In that passage, the Eleatic Stranger is using possession by Eurycles as an analogy for the position of the so-called opsimaths (or 'late-learners'), and their arguments concerning the impossibility of the many to be one and the one to be many. ${ }^{10}$ While the surrounding argument is complex, the simile is straightforward: again, as Alan Sommerstein has observed, it indicates that Eurycles was a spirit that others carried within them (Pl. Soph. 252C).

Because they are obliged in speaking of anything to use the expressions 'to be', 'apart', 'from the rest', 'by itself', and countless others; they are powerless to keep away from them or avoid working them into their discourse; and therefore there is no need of others to refute them, but, as the saying goes, their enemy and future opponent is of their own household whom they always carry about with them as they go, giving forth speech from within them, like the wonderful Eurycles [ton atopon Euryklea]

The language of Plato's description is also helpful here, specifically, the phrase ton atopon Euryklea. This is translated here as 'the wonderful Eurycles' (Sommerstein

$10 \mathrm{Pl}$. Soph. 252B: They are 'the very men who forbid us to call anything by another name because it participates in the effect produced by another' who 'would be made most especially ridiculous by this doctrine' (trans. Fowler here and below). 
1983, ad loc. translates as 'the weird Eurykles'). This underlines how extraordinary is or was the behaviour of this spirit (or, as above, the prophet that possessed him), but perhaps there is some further word play involved, as well. The term atopos can also mean simply 'out-of-place'. This would perhaps be a more fitting adjective for the context: the Eleatic Stranger points out that the arguments of the opsimaths mean that they cannot use the term 'is', which puts them in an impossible position, 'Because they are obliged, in speaking of anything, to use the expressions "to be”, "apart", "from the rest", "by itself”, and countless others; they are powerless to keep away from them or avoid working them into their discourse.' The Eurycles analogy thus provides an image for the way in which the sophists' own language carries the arguments of their opponents within it, and, in that context, the description of Eurycles as atopos or 'out-of-place' reinforces this argument. But it also inadvertently further illuminates the concept of possession, since (drawing here on the language used in this passage to describe the opsimaths' arguments) it is an image of something 'apart' and 'by itself', which is, simultaneously, intermingled with what surrounds it. This image of possession, by drawing attention to the presence of the supernatural body as both embodied and disembodied, also creates the objectification of the mortal body. Moreover, in this formulation, the alien and threatening nature of this idea is powerfully reinforced by the image of the enemy who already dwells within the household, and how this presence makes it impossible to avoid, in the end, betraying oneself. ${ }^{11}$

Altogether, these passages suggest that the idea of possession was one that prompted both individual and broader cultural reflection and reflexivity. In these narratives, we find a possessed character depicted as disconnected from their own words and actions, perhaps even threatened, by the presence of a supernatural entity. We cannot of course describe the individual characters as they experience distanciation, as Lambek does Ali, since we do not have evidence that provides such first-person insights. But it is possible to argue that these narratives model a process of distanciation, providing powerful descriptions that evoke aspects of the experience, be they observable physical indications, such as heavy breathing or frenzy; or reports of internal symptoms, such as pain; or imagery, for example, comparing the presence of another individual within the body to an enemy within the household.

11 This naturally also prompts thought of the rhetoric of Lysias 1, in which a man pleads to be found not guilty for killing his wife's lover. In that speech, the enemy within the household is not only the lover who has inveigled his way into the home, but also the child he may potentially engender in the defendant's wife. 
A number of these narratives also provide examples of reflexivity around the phenomenon of possession. The nature of this reflexive discussion varies, as we might expect, by genre: tragedy, in particular, has a form that encourages reflexivity, especially, but not only, through the meditations of the Chorus. For example, in Aeschylus' Agamemnon, Cassandra herself demonstrates reflexivity, considering her own role in the divine plan that she foretells. ${ }^{12}$ Witnessing her possession prompts the chorus to meditate on their own situation and the nature of man and his fate (Aesch. Ag. 1331-42). Comedy, too, is able to provoke reflexivity, using similar dramatic techniques, albeit to different ends. In the passage from Wasps, the Chorus Leader appeals for the audience's support for the playwright, who is compared first with an inspiring spirit, then with a mythical hero, facing down politicians, who are in turn, described as monsters (Sommerstein 2002). The Chorus Leader's initial comparison of the poet to a possessing spirit, inspiring other writers, positions the poet as secretly, almost supernaturally, powerful, and again implies the objectification of the body of the possessed, inhabited by the possessing; person and speech are separated. But in this analogy, the disembodiment of possession is reversed: the connection between the person and their words is remade, when the poet is writing his own poetry openly (phaneros), running risks on his own account (kath' heauton), 'holding the reins of Muses of his own, not someone else's'. Indeed, not only is he thus reintegrated, he is also whole in the sense that he is courageous, a guardian against evils (alexikakos) (Ar. Vesp. 1043).

Whether presented for comic, tragic, philosophical, or medical purposes, narratives of possession reveal a cultural understanding of how the presence of the supernatural could splinter the self. Insofar as they evoked the objectification of mortal and supernatural bodies, these narratives modelled for their audience the process of distanciation, with all the risks that entailed; in turn, through the forms provided by their different genres, they provoked, I would argue, both reflection and reflexivity on the relationship between mankind and gods. But the experience of possession was rare: a more common experience was the consultation of the possessed. In what follows, I want to argue that those seeking oracles would also have experienced the distanciation created by the co-presence of the supernatural.

12 E.g. Aesch. Ag. 1314-20 (trans. Smyth): 'Nay, I will go to bewail also within the palace my own and Agamemnon's fate. Enough of life! Alas, my friends, not with vain terror do I shrink, as a bird that fears a bush. After I am dead, bear witness for me of this - when for me, a woman, another woman shall be slain, and for an ill-wedded man another man shall fall. I claim this favor from you now that my hour is come.' 


\section{The consultant}

In trying to understand what the process of oracular consultation offered its users, scholars have tended to argue that it provided a sense of reassurance and control. ${ }^{13}$ While there is much to be said for this argument, it is interesting to note how it resonates with current ideas of the self - as an autonomous, decision-making agent, who aspires to increasing self-direction - and posits an understanding of ancient Greek selfhood that may be of marked appeal to our modern-day sensibilities. Indeed, it elides a puzzling dilemma posed by our ancient sources, which suggest that while individuals sought some direction from an oracle, they did not necessarily understand it as providing them with greater autonomy. As an example, consider the interaction between Socrates and Xenophon at the beginning of the Anabasis: Socrates makes it clear that Xenophon has asked the oracle the wrong question, but will nevertheless have to carry out its instruction (Xen. Anab. 3.1.5-3.1.8).

In this part of the essay, and building on the arguments of my previous articles (as described above in the first section of this essay), I would like to challenge the current characterization of oracular consultation, and suggest instead that the process of consultation did not, or not only, move options into the world of enquirers - as one commentator has put it (Iles Johnston 2005, 301). Rather, or in addition, it 'moved' the self, or rather, the self-perception of the self. I will argue that this was achieved, at least in part, through processes of distanciation that encouraged individuals to consider themselves in objectified terms within the process of oracular consultation - a process that drew particular attention to the role of the divine in crafting the course of a mortal life.

It could be argued that such a reperceiving of self would begin as soon as an individual set out to consult an oracle: the decision was one that demonstrated a move from reflection to reflexivity. It revealed a capacity to detach oneself from a simple awareness of self-in-a-state-of-uncertainty (reflective), requiring one to envision oneself as an individual who might enter the process of seeking divine help and be changed (reflexive). The separation of self-as-ritual-enquirer from self-as-everyday-actor was also an embodied process, marked by a series of ritualized actions, including preparation for travel to a sanctuary, as well as those rituals, more strictly defined, that took place within the sanctuary, such as purification and sacrifice. In this context, oracle stories might be regarded simply as records of previous consultations; in some cases they would have provided

13 For example, and drawing from recent literature: Johnston 2005, 301; Burkert 2005, 30; Dillon 2017, 37 highlights reassurance, hope and guidance. 
guides to correct ritual behaviour and attitudes. But I want to suggest that they played a further crucial role: helping to generate the self as oracular consultant. By providing a narrative structure within which to frame the experience of oracular consultation, they created what we might think of as a feedback loop, drawing those who were consulting an oracle into a process of reflexive self-textualization.

\subsection{Self and other (self)}

We start with the evidence of the oracle stories: exegetical narratives that circulated in both oral and written forms. These narratives were created, in the first instance at least, either as part of the ritual that took place within the oracular sanctuary or as part of the ritual of transmission by means of which the oracles were transformed into oracle stories and then transmitted across wider society. ${ }^{14}$ As noted above, we may argue, with Lisa Maurizio, that the verse-oracle type of oracular statement that is recorded in, for example, Herodotus' Histories, was produced by the Pythia (Maurizio 1995; 1997); or we may prefer (with Hugh Bowden, for example), to think of this type as the product of the telling of an oracle story, developed after a consultation event that had in fact produced a much simpler response (Bowden 2005).

The details of the process of production of these stories are of less importance to the argument of this essay than the fact of their circulation, on which I will focus here. ${ }^{15}$ However they were originally formulated, the oracle stories were, through their repetition and transmission, repeatedly reconstituted in a new context, where they demanded a novel engagement from a broader audience (Barber 2003, 326). The circulation of these stories suggests that they were themselves sources of reflection: their existence suggests, as Barber puts it (in discussion of African oral genres), 'a consciousness of text as something created in order to be expounded, recontextualized and reflected upon' (ibid.). But we can also argue that they were prompts to a crucial reflexivity. Within the texts themselves, the

14 Of course, the process of their production is significant: in the case of the former, that is, if these are the words of the Pythia, then this is a process of entextualization, in which these oracle verses are reconstituted in a new context, where they demand a novel engagement from a broader audience (see Barber 2003, 326); in the case of the latter, the development of stories from simple monosyllabic responses by the Pythia would add a significant layer of exegesis to the process of entextualization, but exegesis that includes riddling is exegesis that obscures rather than explains, and which, in turn, requires further exegesis (the resolution of the riddle).

15 If these verses do represent the words of the Pythia, then this is a process of entextualization, defined as 'the process of rendering a given instance of discourse as text, detachable from its local context' (Silverstein 1996, 21). 
content of these stories, even those of clearly mythical origin, resonated with reallife concerns. As an example, consider the many questions posed by individuals at Dodona about their hopes for children, and how these same anxieties appear in the stories of Kings Aigeus, Laios, Akrisios, Xuthos and Kephalos. ${ }^{16}$ But as well as drawing out shared experiences, these stories set the individual in a larger cosmological context than the everyday, since they also described, implicitly or explicitly, the intersubjectivity of mortal and divine. Not only did these stories describe episodes of possession (in the person of the Pythia), but they also made it clear that the gods and other supernatural forces were profoundly involved in the co-creation of the course of each mortal life.

As grist for this reflexivity, oracle narratives conveyed a strong sense of the resulting indeterminacy of the oracular consultation. These narrative framings of the experience of oracular consultation juxtaposed mortal concerns and mortal ignorance with divine knowledge, and underlined the gulf that existed between the two. In these stories, the oracular solution did not necessarily respond to the question that an individual had asked; what an individual heard at an oracle, he or she might well not understand. Indeed, in these stories, the central message could even be phrased as a riddle, from which the 'hidden meaning' must be elicited.

This aspect in particular resonated with both the context and the form of actual oracular consultations. By this, I do not mean that the responses to real-life consultations were (necessarily) delivered as riddles. Rather, the complexity (whatever its form) of oracles in oracle stories indicated that actual oracular pronouncements might also have needed to be 'worked out'. This narrative element reinforced the cosmological context of consultation, specifically the distance between mortal and divine knowledge. ${ }^{17}$ In turn, as I have argued (see above), there is a surprising emphasis on the presence of $T / t u c h e$ in the oracular question

16 Aegeus of Athens: Plut. Thes. 3.5; Apollod. 3.15.6; Eur. Med. 679, 681 (cf. for detailed references Fontenrose L4). Laios: Eur. Phoen. 17-20 (1598 f.); Soph. OT 713 f., 853 f., 1176 (906-8) (cf. for detailed references Fontenrose L17). Akrisios: Pherekydes 3.10J (cf. for detailed references Fontenrose L23). Xuthos: Eur. Ion 70 f., 534-7, 787 f., 1533 (cf. for detailed references Fontenrose L28). Kephalos: Arist. Fr. 504 (Rose) (cf. for detailed references Fontenrose L82). For examples of the questions asked at Dodona see Eidinow 2013.

17 Maurizio 2001, 40, n. 14 suggests that only a third of the oracles we possess are likely to have been ambiguous. It is worth noting that even a 'yes/no' response from an oracle will require discussion of meaning in the sense of what actions should follow. A similar observation is made by Karin Barber in her analysis of Yoruba divinatory texts (1999, 31; her italics): 'Yoruba texts [...] are made up of free-standing elements that signal that they require or are capable of completion or expansion that is not necessarily performed within that text at that moment. That is, they function as citations of something larger which is not actually present.' 
tablets from Dodona, suggesting that those who visited the oracle did not expect the outcomes of their consultations (i.e., the responses they received) simply to be fulfilled. The idea that the gods' meaning or intent might emerge unexpectedly was also reflected in the form taken by real-life consultations, which in their formulation, acknowledged the broader unseen forces shaping future events.

The implications of these observations are that, while an individual may have turned to an oracle for guidance about the future, we should be cautious in suggesting that their aim was simply and straightforwardly to acquire a sense of control. Indeed, the aesthetic of the oracle narratives was intrinsically ironic, and I would suggest that it was matched in actual oracular consultations by a strong sense of reflexivity and (related) indeterminacy. ${ }^{18}$ Turning back briefly to Lambek's work, we see how, in the example of his case study's illness (which he regards as an art form equivalent to a narrative), this 'invites all who encounter it to contemplate agency and its limits, dignity and its vicissitudes, individuality and its relational entailments, hope and contingency, the essential uncertainty of life' (Lambek 2003, 55). Such moments of reflection on and dialogue with oneself are opportunities for questioning the status quo, with regard to both the natures of oneself, or selves - the self that observes and the other that is observed - and the structures within which those selves operate. In Lambek's case study, an illness could raise questions for his subject (Ali), indicating how his life could be different if his physical body was different. An oracular consultation is, in a similar way, likely to have been an occasion that provoked reflexive consideration about the self as other, and on the multiple, possible other lives - and other selves - that might emerge as a result of interaction with the divine.

\section{Conclusion}

This essay is part of a larger argument that oracular consultation was not, or not only, a way of achieving self-mastery or a greater sense of agency, as is commonly argued in scholarship. Rather, it suggests, oracular consultation would have involved acknowledgment of the intersubjective nature of the self, and engagement with a sense of uncertainty, especially in situations of risk. I have argued elsewhere that an oracular consultation was an event that marked the multiple different social and cosmic forces that shaped who a consultant was and the course of his or her life. Here, I have tried to explore the possible experiences

18 Babcock 1980, 5. As Babcock has observed, there is an 'intimate connection between reflexivity and indeterminacy.' 
of those who participated in these rituals, examining possession and oracular consultation as activities that resulted in processes of distanciation and reflexivity. As a result, rather than (or as well as) eliciting a sense of control, oracular consultation was an experience through which an individual, who conceived of herself as embedded in a larger social and cosmological nexus, would confront the indeterminacy of her future and the forces shaping it.

Realising that this argument goes against current trends in scholarship on this subject, I end with a final suggestion, which includes some consideration of contemporary views of the self. One of the reasons why we, in modern times, find oracle consultation so compelling is that it challenges the overriding cultural conception of the individual - as an autonomous agent exercising rational choice. It would be easy to accept this characterisation and, in response, to dismiss ancient Greek ritual practice as 'superstitious', but the answer may not be so simple. Instead, I would like to suggest that the fascination that oracles still provoke arises, at least in part, because they reveal a more uncomfortable possibility: our underlying sense of ourselves as composite, that is, as constituted by a network of visible and invisible relations, and the resulting limits of our own agency and knowledge.

\section{References}

Babcock, Barbara A. 1980. 'Reflexivity: Definitions and Discriminations', Semiotica 30.1/2.1-14. Barber, Karin. 1999. 'Quotation in the Constitution of Yoruba Oral Texts', Research in African Literatures 30.2. 17-41.

Barber, Karin. 2003. 'Text and Performance in Africa', Bulletin of the School of Oriental and African Studies 66.3. 324-33.

Boddy, Janice. 1998. 'Afterword: Embodying Ethnography'. In Bodies and Persons: Comparative Perspectives from Africa and Melanesia, eds. Michael Lambek and Andrew Strathern, Cambridge: Cambridge University Press. 252-73.

Bouché-Leclerque, Auguste. 1880. Histoire de la Divination dans l'Antiquité III. Paris.

Bowden, Hugh. 2003. 'Oracles for Sale'. In Herodotus and His World: essays from a conference in memory of George Forrest, eds. Peter Derow and Robert Parker. Oxford: Oxford University Press. 256-74.

Bowden, Hugh. 2005. Classical Athens and the Delphic Oracle: Divination and Democracy. Cambridge: Cambridge University Press.

Bremmer, Jan N. 1984. 'Greek Maenadism Reconsidered', Zeitschrift für Papyrologie und Epigraphik 55. 267-86.

Burkert, Walter. 1985. Greek Religion: Archaic and Classical. Oxford: Oxford University Press.

Burkert, Walter. 2005. 'Signs, Commands and Knowledge: Ancient Divination between Enigma and Epiphany'. In Mantikê: Studies in Ancient Divination. Religions in the Graeco-Roman world 155, eds. Sarah Iles Johnston and Peter T. Struck. Leiden: Brill. 29-49. 
Chalupa, Aleš. 2014. 'Pythiai and Inspired Divination in the Delphic Oracle: Can Cognitive Sciences Provide Us with an Access to "Dead Minds"?', Journal of Cognitive Historiography 1.1. 24-51.

Deeley, Quinton. 2019. 'The Pythia at Delphi: A Cognitive Reconstruction of Oracular Possession'. In Ancient Divination and Experience, eds. Lindsay Driediger-Murphy and Esther Eidinow. Oxford: Oxford University Press.

Dillon, Matthew. 2017. Omens and Oracles: Divination in Ancient Greece. London/New York: Routledge, Taylor \& Francis.

Dodds, Eric R. 1951. The Greeks and the Irrational. Berkeley: University of California Press.

Eidinow, Esther. 2007. Oracles, Curses, and Risk among the Ancient Greeks. Oxford: Oxford University Press.

Eidinow, Esther. 2013. 'Oracular Consultation, Fate, and the Concept of the Individual'. In Divination in the Ancient. World: Religious Options and the Individual, ed. Veit Rosenberger. Stuttgart: Steiner. 21-39.

Eidinow, Esther. 2019a. 'Túx $\alpha$ at the Oracle of Zeus, Dodona'. Zeitschrift für Papyrologie und Epigraphik 209. 91-102.

Eidinow, Esther. 2019b. 'Testing the Oracle? On the Experience of (Multiple) Oracle Consultations'. In Ancient Divination and Experience, eds. Lindsay Driediger-Murphy and idem.

Flacelière, Robert. 1938. 'Le fonctionnement de l'oracle de Delphes au temps de Plutarque'. In Études d'Archéologie Grecque: À Robert Werner, ed. Yves Béguinon. Gand: École des Hautes Études. 69-107.

Flower, Michael A. 2008. The Seer in Ancient Greece. Berkeley: University of California Press.

Fontenrose, Joseph. 1978. The Delphic Oracle: Its Responses and Operations with a Catalogue of Responses. Berkeley: University of California Press.

Geertz, Clifford. 1983. Local Knowledge: Further Essays in Interpretive Anthropology. New York: Basis Books.

Graf, Fritz. 2009. 'Apollo, Possession, and Prophecy'. In Apolline Politics and Poetics: International Symposium, eds. Lukia Athanassaki et al. Athens: European Cultural Centre of Delphi. 587-605.

Hornblower, Simon. 2015. Lykophron: Alexandra. Greek Text, Translation, Commentary, and Introduction. Oxford: Oxford University Press.

Iles Johnston, Sarah. 2005. 'Delphi and the Dead'. In Mantikê: Studies in Ancient Divination. Religions in the Graeco-Roman world 155, eds. idem and Peter T. Struck. Leiden: Brill. 283-306.

Lambek, Michael. 1981. Human Spirits: A Cultural Account of Trance in Mayotte. Cambridge: Cambridge University Press.

Lambek, Michael. 1988. 'Spirit Possession/Spirit Succession: Aspect of Social Continuity among Malagasy Speakers in Mayotte', American Ethnologist 15.4. 710-31.

Lambek, Michael. 1993. Knowledge and Practice in Mayotte: Local Discourses of Islam, Sorcery, and Spirit Possession. Toronto: University of Toronto Press.

Lambek, Michael. 1998. 'Body and Mind in Mind, Body and Mind in Body: Some Anthropological Interventions in a Long Conversation'. In Bodies and Persons: Comparative Perspectives from Africa and Melanesia, eds. Michael Lambek and Andrew Strathern. Cambridge: Cambridge University Press. 103-23.

Lambek, Michael. 2002. The Weight of the Past: Living with History in Mahajanga. New York: Palgrave Macmillan. 
Lambek, Michael. 2003. 'Rheumatic Irony: Questions of Agency and Self-deception as Refracted through the Art of Living with Spirits', Social Analysis: The International Journal of Social and Cultural Practice 47.2. 40-59.

LiPuma, Edward. 1998. 'Modernity and Forms of Personhood in Melanesia'. In Bodies and Persons: Comparative Perspectives from Africa and Melanesia, eds. Michael Lambek and Andrew Strathern, Cambridge: Cambridge University Press. 53-79.

Lehoux, Daryn. 2007. 'Drugs and the Delphic Oracle', Classical World 101.1. 41-56.

Lynch, Michael. 2000. 'Against Reflexivity as an Academic Virtue and Source of Privileged Knowledge', Theory, Culture, and Society 17. 26-54.

Maurizio, Lisa. 1995. 'Anthropology and Spirit Possession: a Reconstruction of the Pythia's Role at Delphi', Journal of Hellenic Studies 115. 69-86.

Maurizio, Lisa. 1997. 'Delphic Oracles as Oral Performances: Authenticity and Historical Evidence', Classical Antiquity 16. 308-34.

Maurizio, Lisa. 2001. 'The Voice at the Center of the World: the Pythias' Ambiguity and Authority'. In Making Silence Speak: Women's Voices in Greek Literature and Society, ed. André P. M. H. Lardinois. Princeton: Princeton University Press. 38-54.

McLeod, Wallace E. 1961. 'Oral Bards at Delphi', Transactions of the American Philological Association 92. 317-25.

Parke, Herbert W. and Donald E. W. Wormell. 1956a. The Delphic Oracle I. The History. Oxford: Blackwell.

Parke, Herbert W. and Donald E. W. Wormell. 1956b. The Delphic Oracle. II. The Oracular Responses. Oxford: Blackwell.

Price, Simon R. F. 1985. 'Delphi and Divination'. In Greek Religion and Society, ed. Patricia E. Easterling. Cambridge: Cambridge University Press. 128-54.

Silverstein, Michael (ed.). 1996. Natural Histories of Discourse. Chicago: Chicago University Press.

Sommerstein, Alan H. 1983. The Comedies of Aristophanes, Vol. 4: Wasps. Warminster: Aris \& Phillips.

Sommerstein, Alan H. 2002. 'Monsters, Ogres and Demons in Old Comedy'. In Monsters and Monstrosity in Greek and Roman Culture, Nottingham Classical Literature Studies Midland Classical Studies 6, ed. Catherine Atherton. Bari: Levante. 19-40.

Stausberg, Michael. 2006. 'Reflexivity'. In Theorizing Rituals. Vol. 1: Issues, Topics, Approaches, Concepts, eds. Jens Kreinath, Joannes Snoek and idem. Leiden: Brill. 627-46.

Strathern, Marilyn. 1988. The Gender of the Gift: Problems with Women and Problems with Society in Melanesia. Berkeley: University of California Press.

Strauss, Claudia and Naomi Quinn. 1997. A Cognitive Theory of Cultural Meaning. Cambridge: Cambridge University Press.

Trilling, Lionel. 1971. Sincerity and Authenticity. Cambridge, MA: Harvard University Press. Whittaker, Charles R. 1965. 'The Delphic Oracle: Belief and Behaviour in Ancient Greece and Africa', Harvard Theological Review 57. 21-47. 